\title{
Car Decals as a New Data Source for Self-Drive Tourists
}

\section{RALF BUCKLEY}

International Centre for Ecotourism Research, Griffith School of Environment, Gold Coast campus, Griffith University, Qld 4222 Australia. Telephone +61 (0)7 55528675 , Facsimile +61(0)7 5552 8895, $\underline{\text { r.buckley@griffith.edu.au }}$

\section{CLAUDIA OLLENBURG}

School of Hotel, Resort and Tourism Management, Bond University, Qld 4229, Australia. E-mail: collenbur@bond.edu.au 


\section{Car Decals as a New Data Source for Self-Drive Tourists}

\section{Introduction}

Self drive domestic tourism is one of the largest subsectors of the tourism industry. According to the US Travel Association, 85\% of overnight trips in the USA are self drive travel (Mandala 2011). In Australia, self-drive tourism is a major component of the large and often underestimated VFR travel subsector (Backer 2011). Self-drive travellers make up a major component in many economic valuations of recreational demand (Fleming and Cook 2008). Shifts between driving and other modes of transport may be a critical aspect of the interactions between tourism and climate change (Becken and Wilson 2007; Koo et al. 2010).

Self-drive routes and destinations can be tracked by using GIS systems (Höpken et al. 2009) and modelled using network analysis (Shih 2006) or similar approaches (Liu et al. 2011). This identifies where self-drive tourists go, but not what they do. Large scale national surveys such as those by the Outdoor Recreation Industry Council (2011) indicate what activities a country's citizens claim to take part in over the course of the year, but generally not when and where they do so. Recreational activity preferences for commercial tour clients can be inferred directly (Buckley 2007), but this is a smaller subsector. For self-drive tourists, there has generally been no straightforward way to determine recreational activity preferences, except by intercepting them and asking them directly (Becken and Wilson 2007; Lane and Waitt 2007; Prideaux and Carson 2003).

A fashion which has become prevalent over the past couple of years provides a new source of data, which is examined here. This is the practice of displaying customised commercially made decals on car windows, entitled "My Family", with cartoon representations of family members equipped for their preferred recreational activities. These decals are readily available at newsagents or fuel stations. They tell us how the individuals concerned, or at least the owners of the cars, perceive themselves at play. A total of 127 symbols are available, with 8 showing grandparents, 35 of parents, 26, 22 and 10 showing older, mid-aged and younger children respectively, 4 of babies, and 22 of pets.

For adults and children, half of each category show males, half females. Some symbols do not show any identifiable recreational activity, and two (one male, one female) show a person using a computer. Of the remainder, some activities are shown only for one gender, and some 
only for specific age groups. In particular, there are male parent symbols indicating golf and barbecuing, and female parent symbols indicating shopping and running, with no opposite gender equivalents. Similarly, symbols for cricket, skateboarding, playing drums, and running around in a Superman cape are available only for male children of appropriate ages, and symbols for dancing only for female children. Most organised sports, such as rugby, soccer and tennis, are shown for both genders, as are individual outdoor recreation activities such as surfing.

\section{Methods}

A total of 1505 vehicles were first surveyed to determine what proportion bear the "My Family" decals. Vehicles without an appropriately configured rear window were excluded. One hundred and eighty vehicles bearing decals were then recorded in detail, ignoring nondecal-bearing vehicles. These 180 vehicles were recorded at traffic lights on the two main north south highways of the Gold Coast region in southern Queensland (Qld), one of Australia's principal tourist destinations. Other options, such as car parks, risk bias since people with particular recreational interests may congregate preferentially in particular areas. Highways avoid this potential bias, since tourists and locals alike use them routinely and unavoidably.

For each vehicle, the following data were recorded: (a) in state (Queensland) or out of state registrations; (b) sedan, station wagon, utility (pickup) or four wheel drive; and (c) approximate value, allowing for age, in three bands (cheap, mid, luxury). For the decals, the gender, recreational activity, and age category of each individual shown was recorded. Three successive analyses were carried out on this 180-vehicle Gold Coast data set. The first simply outlined the structure of families depicted, i.e. the number and gender of individuals in each age group. The second examined the frequencies of different recreational activities depicted. The third tested for any differences between in-state and out-of-state samples, as a surrogate for locals cf tourists.

In addition, we carried out separate and more finely focused analyses on two particular recreational activities, namely surfing and horse-riding. Surfing was selected since it was the most frequently-shown recreational activity, in the main 180-vehicle data set, for which both male and female decals were available. This second analysis was based on two further sets of 
decal-bearing vehicles in the adjacent northern region of the neighbouring State of New South Wales (NSW). One set, with 18 decal-bearing vehicles (i.e. 1800 vehicles in all), was scored on the main road in and out of the tourist town of Byron Bay. The second, with 13 decalbearing vehicles, was scored at oceanfront car parking areas at a series of smaller settlements in the Tweed Shire, NSW, between Byron Bay and the Gold Coast. Both these sets of vehicles were scored only for two characteristics: Qld or NSW licence plates, and presence or absence of decals representing surfing.

Horse riding is a popular recreational activity for residents in the hinterland region inland from the main Gold Coast urban conglomeration. Many residential properties in these areas are so-called acreage blocks, and many of these include areas of former farmland which are large enough to keep horses. Such opportunities are not available in the coastal urban area. Access to public lands for horse riding is a politically contentious issue in the Gold Coast and adjacent regions. Further inland again, in the neighbouring local government area, there are horse studs, agistment properties, and polo and racing establishments, a great deal more upmarket than the suburban acreage blocks in the Gold Coast. There are also farm tourism operations offering horse riding as a commercial activity (Ollenburg and Buckley 2011). There is no decal for horse riding as such, but there is a decal for a horse. We therefore tested whether horse symbols are more frequent on vehicles observed on roads through the hinterland acreage areas than on the main urban highways.

\section{Results}

Of the 1505 vehicles initially surveyed, decals were present on 15, i.e. $\sim 1.0 \%$. For the 180 vehicles where characteristics of the vehicle and decals were recorded in detail, family sizes are shown as ranging from one to eight, with mean size 3.80 and median 4.0: two parents and two children. Very few grandparents are shown, and only a small number of single parent families. Babies are shown for one family in seven. Pets are shown for 55\% of families, with a single pet in $28 \%$ of cases and successively smaller number of families with larger numbers of pets, up to six in one or two instances. Dogs and cats are featured most frequently, but fish, birds and horses are also shown. Many of the pet symbols available were not used at all.

Only a small proportion of the available recreational symbols were used with any frequency. Golf, bike riding, gardening, reading and diving are shown for $<1 \%$ of individuals 
represented. Just over one third (34\%) of the individual adults and children shown are represented by symbols with no specific recreational activity. In total, $45 \%$ of females are shown either running or shopping, and one third of males are shown either fishing, skateboarding, weightlifting or barbecuing. These symbols are not available for the opposite gender. About $8 \%$, in both genders, are shown with computers.

For those individuals shown as engaged in recreational activities which are pictured for both genders, approximately $43 \%$ are shown with surfboards, $29 \%$ engaged in organised sports, and $28 \%$ in some form of dance or musical activity. Half $(50 \%)$ of the active women are shown in music or dance-related activities, cf only $7 \%$ for men, but there are many more female than male symbols available in this category. Symbols for organised sports are available equally, and there is little difference between genders, with $25 \%$ of active females and $33 \%$ of active men in this category. Perhaps the most interesting category is surfing. Surfing is the recreation indicated for $60 \%$ of male and $25 \%$ of female individuals shown as engaged in active recreation available equally to both men and women. This is the highest frequency for any of the gender-neutral recreation types.

There were no significant differences in any of the patterns described above between vehicles of different type or value. Nor were there any detectable differences between local and tourist vehicles as regards family size and composition, proportions of decals showing a recreational activity of some form, the frequencies of less common activities such as golf or gardening, or the frequencies of nationally-widespread activities such as organised sports.

The most critical test is thus provided by the relative frequency of surfing symbols, both male and females, on in-state cf out-of-state vehicles. The Gold Coast is one of Australia's premier recreational and competitive surfing destinations, popular with residents and tourists alike. Adjacent but less heavily populated areas of northern NSW, including Byron Bay and the coastline between Byron Bay and the Gold Coast, also possess points and beaches popular for beach and ocean recreation including surfing, fishing and diving. Both towns are also popular for sunbathing, shopping and socialising. Residents of Qld frequently drive to NSW, and vice versa. Since southeast Qld has many more residents than northeast NSW, however, the flow of self-drive tourists from Qld to NSW is larger than the reverse, with consequent effects on the relative frequency of Qld car licence plates in northern NSW. Therefore, the frequency of 
surfing decals on Qld vehicles in northern NSW provides a more powerful comparison of tourists cf residents, in a statistical sense, than for NSW vehicles on the Gold Coast.

Only about $1 \%$ of cars display decals, and most of the oceanfront car parking areas between Byron Bay and the Gold Coast have maximum capacity of around 100 vehicles. These areas are heavily frequented by surfers on days with good surf. On days with little surf, they are less heavily frequented, often for recreational fishing. Therefore, to achieve a sufficiently powerful test, an aggregate sample was compiled from all of these intermediate areas for several days of good surf. The aggregate sample of 13 decal-bearing vehicles at these sites represents approximately 1300 vehicles in total. Similarly, the 18 decal-bearing vehicles from Byron Bay represent approximately 1800 vehicles in total. Since Byron Bay is commonly crowded with cars, however, that sample was simple to obtain.

Results were as follows. Both for the 180 decal-bearing vehicles recorded on the Gold Coast, and the 18 vehicles at Byron Bay, there were no significant differences in the frequencies of surfing decals between cars with in-state or out-of-state licence plates. For the 13 decalbearing vehicles at the smaller oceanfront sites in northern NSW, however, there was indeed a statistically significant difference ( $p<0.05$, Fisher's exact test). Six of these were from Qld, and all these were surfers. Seven were from NSW, and of these only 2 were surfers. The remainder of the NSW decals showed a range of unrelated activities, suggesting that these were simply local residents who happened to be visiting the beach briefly.

For horse riding, we did not find any significant differences between cars observed in urban areas where horses are not kept, and hinterland areas where they are. Horse decals, however, occur only on a small proportion $(<2 \%)$ of decal-bearing vehicles, which are themselves only $\sim 1 \%$ of all vehicles. Unlike surfing, therefore, for horse riding the decals simply do not sample a large enough proportion of the population to carry out statistically significant tests of geographic patterns.

\section{Discussion}

These vehicle decals do indeed provide a new and valuable source of data on people's self perception and self representations of leisure and recreational activities for the self-drive tourist market. They are displayed by families of all sizes, including single individuals. If car 
value is an indicator of socio-economic status, they cross every stratum of Australian society. They are restricted to activities for which decals are available, but since many types of decal are unused, this does not seem to be a limitation.

These data do have a number of potential limitations, albeit minor. They are available only for individuals who choose to advertise themselves in this way. They may reflect principally what people do at home, which is not necessarily what they do on holiday. Car number plates are only a surrogate means to distinguish residents from tourists. Tourists from elsewhere in Queensland, as well as Gold Coast residents, have in-state registration. The southern end of the Gold Coast urban conglomeration region spills over into the adjacent state, so not all outof-state plates are necessarily tourists. These, however, are quantitatively small effects, simply because of the size of the main Gold Coast population. They do not apply for the more focused sampling of surfers in northern NSW.

Overall, therefore, it appears that this new fashion can provide an additional source of data for a large but hard-to-study sector of the domestic tourism market. Like all fashions, it may grow, or it may fade. In addition, it may become subject to ironic reinterpretations. But at the moment, it is useful. 


\section{References}

BACKER, E. (2011). VFR Travel: It is Underestimated. Tourism Management 33(1): 74-79. doi: 10.1016/j.tourman.2011.01.027

BECKEN, S. and WILSON, J. (2007). Trip Planning and Decision Making of Self-Drive Tourists. Journal of Travel and Tourism Marketing 20(3/4): 47-62.

doi: 10.1300/J073v20n03_04

BUCKLEY, R. C. (2007). Adventure Tourism Products: Price, Duration, Size, Skill, Remoteness. Tourism Management 28: 1428-1433.

FLEMING, C. M. and COOK, A. (2008). The Recreational Value of Lake McKenzie, Fraser Island: An Application of the Travel Cost Method. Tourism Management 20(6): 1197-1205.

HÖPKEN, W., GRETZEL, U., LAW, R., HOLYOAK, N., CARSON, D. and SCHMALLEGGER, D. (2009). VRUM: A Tool for Modelling Travel Patterns of Self-Drive Tourists. In Höpken, W., Gretzel, U. and Law, R. (eds) Information and Communication Technologies in Tourism 2009. Vienna: Springer Vienna: 237-247

DOI: 10.1007/978-3-211-93971-0_20.

KOO, T.T.R., WU, C-L. and DWYER, L. (2010). Transport and Regional Dispersal of Tourists: Is Travel Modal Substitution a Source of Conflict between Low-Fare Air Services and Regional Dispersal? Journal of Travel Research 40(1): 106-120.

LANE, R. and WAITT, G. (2007). Inalienable Places: Self-Drive Tourists in Northwest Australia. Annals of Tourism Research 34(1): 105-121.

LIU, Y., ZHANG, Y. and NIE, L. (2011). Patterns of Self-Drive Tourists: The case of Nanning City, China. Tourism Management 33(1): 225-227.

doi: 10.1016/j.tourman.2011.01.025.

MANDALA, L. (2011). Project 85 - The Drive Market. http://www.mandalaresearch.com Accessed on 19 August 2011. 
OLLENBURG, C. and BUCKLEY, R. (2011). Which Farmers Turn to Tourism? A Continental-Scale Analysis. Tourism Recreation Research 36(2): 127-140.

OUTDOOR RECREATION INDUSTRY COUNCIL (2011). ORIC. http://www.oric.org.au/ Accessed 19 August 2011.

PRIDEAUX, B. and CARSON, D. (2003). A Framework for Increasing Understanding of Self-Drive Tourism Markets. Journal of Vacation Marketing 9(4): 307-313.

SHIH, H-Y. (2006). Network Characteristics of Drive Tourism Destinations: An Application of Network Analysis in Tourism. Tourism Management 27(5): 1029-1039. 